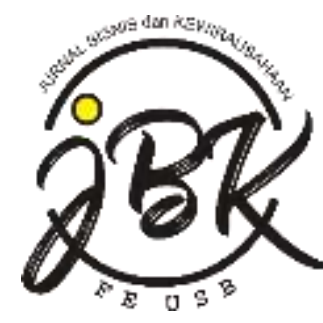

\title{
APAKAH KINERJA KEUANGAN MEMEDIASI PENGARUH INTELLECTUAL CAPITAL TERHADAP REAKSI INVESTOR PADA PERUSAHAAN PERBANKAN DI INDONESIA (?)
}

\author{
Crescentiano Agung Wicaksono ${ }^{1)}$ \\ Akademi Akuntansi YKPN, Yogyakarta \\ (crescentiano.agung@gmail.com) \\ Afni Sirait ${ }^{2)}$ \\ Universitas Pembangunan Nasional "Veteran", Yogyakarta \\ (afni.sirait@upnyk.ac.id) \\ Heri Susanto ${ }^{3)}$ \\ Akademi Akuntansi YKPN, Yogyakarta \\ (herisusanto303@gmail.com)
}

\begin{abstract}
Intellectual capital is vital for companies to improve competitiveness. Company stakeholders are starting to realize that intellectual capital is one of the intangible assets that need to be managed properly because it helps companies compete. This study aims to examine financial performance in mediating the effect of intellectual capital on investor reaction. Financial performance is measured using a return on assets, intellectual capital as an independent variable is measured using value-added Intellectual capital (VAICTM) which consists of three components, namely: human capital, structural capital, and relational capital, while investor reactions are measured using abnormal returns. The object of research is the banking sector companies listed on the Indonesia Stock Exchange (IDX) in 2016-2018 by the determined purposive sampling. This study uses Structural Equation Modeling (SEM) for data analysis and hypothesis testing, and uses the WarpPLS version 7.0 software to process data. Based on the test results, several conclusions: (a) Intellectual has a positive and significant effect on investor reaction, (b) Intellectual capital has a positive and significant effect on financial performance, (c) financial performance has a positive and significant effect on investor reaction, and (d) financial performance can fully mediate the effect of Intellectual capital on investor reactions.
\end{abstract}

Keywords: Intellectual capital, abnormal return, investor reaction

\section{A. PENDAHULUAN}

Era globalisasi menjadi era perkembangan yang pesat dalam hal teknologi, ilmu pengetahuan dan bidang lainnya yang mempunyai dampak besar terhadap aspek kehidupan manusia. Secara khusus, revolusi industri 4.0 yang muncul dalam era globalisasi juga mempunyai pengaruh dalam industri bisnis secara global. Munculnya banyak perusahaan baru membuat persaingan menjadi lebih ketat. Selain persaingan secara kuantitas, perkembangan ilmu teknologi yang terjadi membuat persaingan juga lebih ketat dalam hal kualitas. Kondisi seperti ini menuntut 
semua perusahaan untuk bisa mengikuti perkembangan yang terjadi agar bisa bersaing secara global. Perusahaan perlu mempunyai strategi khusus agar bisa memenangkan persaingan. Perusahaan yang tidak mampu bersaing akan tergusur dan dampak yang paling buruk adalah perusahaan mengalami kebangkrutan.

Usaha perusahaan dalam memenangkan persaingan dilakukan dengan banyak cara, salah satunya dengan investasi aset. Banyak perusahaan mengeluarkan banyak uang untuk membeli aset berteknologi tinggi. Akan tetapi, realita ekonomi saat ini memposisikan intellectual capital (IC) sebagai faktor yang kuat dan vital bagi perusahaan. Pengetahuan menjadi faktor penting bagi perusahaan untuk bisa bersaing secara global. Hal ini berarti intellectual capital perlu ditempatkan pada level yang sama dengan modal finansial dan fisik perusahaan. Sama halnya pada saat era industri yaitu investasi perusahaan difokuskan pada mesin dan pabrik sebagai penciptaan nilai, saat ini karyawan sebagai salah satu intepretasi dari intellectual capital menjadi faktor kunci dalam penciptaan nilai bagi perusahaan. (Pulic, 2004). Organisasi melakukan beragam pendekatan untuk mengeksplorasi pengetahuan agar dapat memanfaatkannya secara optimal. Aspek modal intelektual dimanifestasikan dalam tiga pendekatan, yaitu modal karyawan/manusia, organisasi, dan sosial (Davenport \& Prusak, 1998).
Pengukuran IC yang tepat dan baku belum ditemukan, meskipun pengakuan akan IC semakin meningkat sebagai pendorong penciptaan nilai perusahaan (Chen et al., 2005). Salah satu pendekatan untuk mengukur intellectual capital adalah dengan Value Added Intellectual Coefficient (VAIC ${ }^{\mathrm{TM}}$ ), yaitu pengukuran nilai tambah yang dihasilkan oleh modal intelektual yang dimiliki perusahaan (Pulic, 1998). Sumber daya perusahaan yang menjadi komponen utama adalah physical capital (Value Added Capital Employed - VACE), human capital (Value Added Human Capital - VAHC) dan structural capital (Structutal Capital Value Added - SCVA). Konsep knowledged-based economy (Pulic, 2004) mempunyai tujuan utama yaitu menciptakan value added perusahaan dengan cara melakukan efisiensi dalam kemampuan intelektual sumber daya manusia, modal keuangan, serta modal fisik

Fenomena mengenai intellectual capital di Indonesia mulai berkembang sejak munculnya PSAK No. 19 (revisi 2000) tentang aktiva tidak berwujud. Dalam PSAK tersebut dijelaskan bahwa aktiva tidak berwujud (intangible assets) merupakan aktiva non-moneter yang dapat diidentifikasi dan tidak mempunyai wujud fisik serta dimiliki untuk digunakan dalam menghasilkan atau menyerahkan barang atau jasa, disewakan pihak lainnya, atau untuk tujuan administratif. Secara eksplisit, modal intelektual tidak terdaftar di laporan keuangan, tetapi berdampak positif terhadap kinerja 
perusahaan, dengan demikian mampu menjelaskan hubungan antara informasi, ide, dan karyawan yang tidak terukur (Edvinsson, 1997). Modal intelektual memiliki berdampak pada penciptaan nilai dan peningkatan kinerja keuangan perusahaan dengan berbagai metode yang dikembangkan untuk mengukur hal tersebut (Ozkan et al., 2017). Dengan kata lain, pengotimalan modal intelektual capital perusahaan memberikan manfaat terhadap laba perusahaan yang merupakan tujuan utama perusahaan didirikan. Laba yang tinggi akan menjadi daya tarik tersendiri bagi stakeholders perusahaan, khususnya investor perusahaan. Keberhasilan perusahaan dalam menjalankan operasional secara tidak langsung tercermin dalam laba yang diperoleh. Selain itu, laba menjadi salah satu tolok ukur investor untuk membuat keputusan berinvestasi ke suatu perusahaan. Selain itu, kondisi non finansial dan non finansial perusahaan juga tercermin dari laba perusahaan. Secara rasional, harga saham meningkat ketika permintaan akan saham tersebut meningkat. Reaksi investor akan informasi yang disediakan oleh perusahaan akan mempengaruhi volatilitas harga saham perusahaaan tersebut di pasar modal (Hayati, 2001). Harga saham sebagai gambaran kemakmuran pemegang saham juga menunjukkan nilai perusahaan itu sendiri (Fidhayatin \& Uswati Dewi, 2012). Dengan kata lain, reaksi investor yang dapat mempengaruhi perubahan harga saham dapat mencerminkan nilai perusahaan.
Penelitian terkait pengaruh intellectual capital terhadap reaksi investor yang tercermin dalam harga saham sudah dilakukan secara empiris oleh Paradesia, Ilmi, \& Nadir (2016); Ronaldo, Indriati, \& Fibria (2017); Subaida, Nurkholis, \& Mardiati (2018); William, Gaetano, \& Giuseppe (2019); Yuskar \& Novita (2014). Namun hasil penelitian tersebut belum menemukan hasil yang konsisten. (Ronaldo et al., 2017) menemukan bahwa Intellectual capital berpengaruh positif dan signifikan terhadap abnormal stock return, sedangkan penelitian yang dilakukan oleh (Paradesia et al., 2016; Subaida et al., 2018; Yuskar \& Novita, 2014) menemukan bahwa intellectual capital tidak mempunyai pengaruh yang signifikan terhadap nilai perusahaan. Bahkan, penelitian yang dilakukan oleh William et al. (2019) menemukan bahwa Intellectual capital justru berpengaruh negatif dan signifikan terhadap nilai perusahaan.

Adanya inkonsisten hasil penelitian terdahulu tentang pengaruh intellectual capital terhadap reaksi investor mendorong peneliti untuk melakukan penelitian lanjutan. Peneliti akan menggunakan kinerja keuangan sebagai variabel mediasi untuk menguji pengaruh intellectual capital terhadap reaksi investor. Kinerja keuangan diprediksi mampu memediasi pengaruh intellectual capital terhadap reaksi investor karena investor juga melihat laba perusahaan yang terdapat dalam laporan keuangan sebagai bagian dari pertimbangan investasi. Penelitian yang dilakukan oleh 
(Ligocka \& Stavárek, 2019; Shabani et al., 2013; Wijayanto et al., 2019)(Hidayat \& Topowijono., 2018) menemukan bahwa yang tercermin dalam laporan keuangan menjadi bahan pertimbangan investor untuk melihat kondisi perusahaan dalam jangka panjang (Hidayat \& Topowijono., 2018). Calon investor mempertimbangkan kinerja keuangan perusahaan dalam menentukan pilihan investasi (Christina \& Robiyanto, 2018).

Penelitian ini melihat pengaruh intellectual capital terhadap reaksi investor dengan kinerja keuangan sebagai variabel mediasi pada sektor perbankan di Indonesia. Terdapat beberapa alasan sektor perbankan dipilih sebagai sampel dalam penelitian ini, yaitu: (1) secara umum, karyawan di sektor perbankan "intelectuaclly" lebih homogen dibandingkan dengan sektor ekonomi lainnya; (2) sektor perbankan adalah "intellectually" intensif; dan (3) tersaji data laporan keuangan yang dapat diakses setiap saat.

\section{B. KAJIAN LITERATUR DAN PENGEMBANGAN HIPOTESIS}

\section{Resourced-Based View Theory}

Menurut teori resourced-based view, sumber daya perusahaan menjadi penopang keunggulan kompetitif perusahaan (Johnson, 1999). Oleh karena itu, sumber daya yang dimiliki perusahaan perlu diidentifikasi, diklasifikasi dan dioptimalisasi. Dalam hal ini, sumber daya mencakup aset tidak berwujud dan berwujud yang digunakan secara efektif harga saham dipengaruhi oleh kinerja keuangan perusahaan. Aspek fundamental

dan efisien untuk menerapkan strategi kompetitif (Tarigan et al., 2019). Perusahaan yang mampu mengendalikan asetnya dengan baik akan mencapai keunggulan kompetitif yang berkelanjutan dan mencapai laba. Menurut (Hitt et al., 2001). Sumber daya tak berwujud seperti pengetahuan, akan lebih mungkin menghasilkan keunggulan kompetitif dan nilai tambah dibandingkan dengan aset berwujud. Teori ini dapat menjelaskan pengaruh intellectual capital yang menjadi intangible asset perusahaan terhadap kinerja keuangan. Perusahaan yang mempunyai dan dapat mengelolela sumber daya dengan baik akan mendapatkan laba yang baik dan pada akhirnya investor tertarik untuk membeli saham perusahaan di pasar modal.

\section{Signaling Theory}

Menurut (Ross, 1977) dalam teori sinyal, perusahaan yang beroperasi dengan baik dapat ditandai dengan laporan keuangan yang baik. Informasi laporan keuangan yang diberikan perusahaan kepada pihak eksternal dapat dijelaskan melalui teori sinyal. Asimetri informasi menjadi motivasi utama perusahaan melakukan pengungkapan informasi kepada pihak eksternal. Oleh karena perbedaan kuantitas dan kualitas informasi yang diperoleh pihak internal dan eksternal, manajemen perlu memberikan informasi agar terjadi 
sinkronisasi

perusahaan

informasi.

Manajemen

melaporkan

kewajiban

kondisi dan informasi perusahaan dan diharapkan dapat menjadi pertimbangan investor dalam mengambil suatu keputusan. Informasi yang diberikan manajemen dapat digunakan untuk melihat prospek perusahaan di masa yang akan datang.

Pemberian informasi keuangan kepada pihak eksternal diharapkan dapat menjadi sinyal bagi investor untuk berinvestasi dengan menggunakan laporan keuangan sebagai bahan pertimbangan. Dalam hal ini, teori sinyal dapat digunakan untuk menjelaskan pengaruh kinerja keuangan terhadap reaksi investor. Apabila hasil analisis laporan keuangan menunjukan kinera perusahaan yang baik, maka investor akan tertarik untuk membali saham perusahaam di pasar modal, begitu juga sebaliknya.

\section{Intellectual capital}

Dalam beberapa tahun terakhir, meskipuni/ntellectual capital sudah menjadi perhatian banyak peneliti dan praktisi, masih saja didefinisikan secara beragam. Artinya belum ada kepastian mutlak untuk mendefisinikan intellectual capital. Intellectual capital adalah pengetahuan yang dapat dikonversi menjadi laba ((Harrison \&

Sullivan, 2000). Intellectual capital merupakan semua kumpulan pengetahuan yang digunakan perusahaan untuk keunggulan kompetitif (Subramaniam \&
Youndt, 2005). Meskipun didefinisikan secara berbeda, penelitian yang dilakukan oleh (Reed et al., 2006) menyimpulkan bahwa sumber daya manusia, organisasi dan sosial menjadi komponen penyusun intellectual capital. Meskipun peneliti sebelumnya mungkin tidak menyetujui kategorisasi dan bentuk yang tepat dari IC, ada konsensi yang luas terdiri modal manusia (human capital), modal relasional (relational capital), dan modal structural (structural capital). (Hsu \& Wang, 2012).

Human capital merupakan komponen inti intellectual capital yang terkait dengan kompentensi karyawan, yaitu pengetahuan mereka, keterampilan, pendidikan, serta integrasi komponen tersebut (Kannan \& Aulbur, 2004; Sveiby, 1997). Human capital merupakan aset paling penting perusahaan karena merupakan sumber strategi pembaruan, kreativitas, kapasitas inovasi dan mempertahankan keunggulan kompetitif utama (Bontis et al., 2007; Chi et al., 2016; O'Sullivan \& Schulte, 2007). Human capital memberikan keunikan bagi perusahaan dalam pengembangan nilai tambah produk dalam mendapatkan loyalitas pelanggan (Ghosh \& Mondal, 2009; O'Sullivan \& Schulte, 2007). Structural capital terdiri dari infrastruktur yang mendukung human capital dalam menjalankan fungsinya dan modal abadi yang tetap berada dalam organisasi, bahkan setelah perubahan dalam kepegawaian. Structural capital mencakupp sumber daya strategis seperti budaya, rutinitas, database, proses, paten, dan merek 
dagang (William et al., 2019). Relational capital adalah kemampuan perusahaan untuk menciptakan nilai melalui hubungan yang kompleks dengan pemangku kepentingan eksternal (Joshi et al., 2013; Tsakalerou, 2015). Kunci sukses perusahaan terletak pada kemampuan perusahaan dalam menciptakan pelanggan baru serta pengelolaan hubungan yang berkualitas (Montequín et al., 2006).

Beragam penelitian menyebutkan bahwa intellectual capital merupakan sumber keunggulan kompetitif perusahaan yang tidak terlihat dan merupakan sumber bagi perusahaan dalam mencapai kinerja pasar dan keuangan yang unggul (Dženopoljac et al., 2016; Zhang, 2017). Intellectual capital dapat berkontribusi dalam menjawab perubahan kebutuhan pelanggan serta untuk menanggapi peluang pasar (Liu, 2017). Hal ini dapat terjadi karena intellectual capital memberikan value creation bagi perusahaan yang dapat meningkatkan kinerja.

\section{Reaksi Investor}

Investor adalah badan hukun, kelompok, maupun individu yang melakukan penanaman modal pada suatu unit usaha tertentu. Investor bereaksi terhadap informasi yang diberikan perushaaan, baik informasi yang negatif maupun positif (Ayuni, 2016). Investor memerlukan informasi yang berasal dari peristiwa (event) internal perusahaan aupun peristiwa eksternal perusahaan untuk membentuk portofolio yang optimal. Volume perdagangan dan fluktuasi harga perdagangan seluruh sekuritas pada pasar modal yang efisien dipengaruhi oleh kejadian eksternal perusahaan, sedangkan harga saham perusahaan yang pada akhirnya dapat menghasilkan abnormal return dipengaruhi oleh kejadian internal (Suryawijaya \& Setiawan, 1998).

Dalam melakukan investasi, investor perlu melakukan penilaian serta analisis terhadap perusahaan agar dapat mencapai laba yang maksimal serta menimumkan risiko yang dapat terjadi. Penilaian tersebut menjadi dasar bagi investor dalam mengambil suatu keputusan. Data laporan keuangan dan tahunan dapat menjadi acuan bagi investor dalam melakukan penilaian. Terdapat dua macam analisis yang digunakan dalam melakukan penilaian, yaitu analisis teknikal dan fundamental. Analisis teknikal yaitu analisis yang menggunakan data pasar saham yang meliputi harga, volume transaksi dan waktu (trend naik atau turun) dan biasanya digunakan oleh investor yang ingin berinvestasi jangka pendek, sedangkan analisis fundamental adalah analisis terhadap aspek-aspek fundamental perusahaan yang merupakan gambaran dari kinerja perusahaan (Hidayat \& Topowijono., 2018). Selain itu, seorang investor dapat juga menggunakan informasi laiinnya selain informasi keuangan untuk melihat aktivitas operasional perusahaan yang tercermin dalam laporan tahunan.

\section{Kinerja Keuangan}


Kinerja keuangan adalah gambaran kondisi keuangan perusahaan secara keseluruhan selama periode waktu tertentu (Bhunia et al., 2011). Keberhasilan perusahaan dalam mengelola sumber daya yang dimiliki dapat tercermin dalam kinerja keuangan. Analisis kinerja keuangan adalah proses menentukan karakteristik operasi dan keuangan sebuah perusahaan dari laporan akuntansi dan keuangan. Tujuan analisis tersebut adalah untuk menentukan efisiensi dan kinerja manajemen perusahaan, sebagaiman tercermin dalam laporan keuangan (Bhunia et al., 2011). Tujuan utama pelaporan keuangan adalah memberikan informasi yang berguna bagi kreditor, investor, dan external stakeholder lainnya unutk membuat keputusan yang terkait dengan keuangan. Maka dari itu, pengukuran kinerja keuangan menjadi informasi yang relevan bagi investor untuk membuat keputusan investasi (Anicic et al., 2017).

Dalam konteks era ekonomi baru, intellectual capital menjadi komponen penting bagi perusahaan dalam penciptaaan nilai perusahaan dan penentu utama perusahaan dalam hal keunggulan kompetitif yang berkelanjutan, peluang pertumbuhan dan nilai pasar (Sardo \& Serrasqueiro, 2018; Seyed Ali Akbar Ahmadi, 2012). Keberhasilan suatu perusahaan dalam bersaing akan diungkapkan perusahaan melalui laporan keuangan yang pada akhirnya dapat mempengaruhi investor dalam membuat keputusan untuk berinvestasi di perusahaan tersebut. Investor dapat menganalisis value added yang diperoleh perusahaan atas dimanfaatkannya intellectual capital dalam kegiatan operasi perusahaan. Intellectual capital yang dikelola dengan baik akan meyakinkan investor bahwa perusahaan mempunyai prospek yang baik di masa yang akan datang, hingga pada akhirnya permintaan pasar akan saham perusahaan akan semakin meningkat (Faza \& Hidayah, 2014) Penelitian yang dilakukan oleh (Ronaldo et al., 2017) menemukan bahwa intellectual capital berpengaruh positif terhadap nilai perusahaan dan stock return. Investor akan memberikan respon positif terhadap perusahaan yang mampun mengendalikan dan memanfaatkan intellectual capital secara optimal. Respon investor dibuktikan dengan adanya kenaikan harga saham perusahaan yang pada akhirnya dapat meningkatkan nilai perusahaan.

$\mathrm{H} 1$ : Intellectual capital berpengaruh positif terhadap reaksi investor

Secara eksplisit laporan keuangan tidak menampilkan intellectual capital, tapi mempunyai dampak positif terhadap kinerja, sehingga mengungkapkan hubungan antara karyawan, iden dan informasi (Edvinsson, 1997). Usaha penciptaan nilai dan inovasi yang memungkinkan perusahaan untuk mengalahkan pesaing dan meningkatkan kinerja keuangan tercermin dalam intellectual capital (FitzPatrick et al., 2013). Intellectual capital dapat berkontribusi membantu 
perusahaan dalam melihat peluang yang ada di pasar dan tanggap akan kebutuhan pelanggan (Liu, 2017). Dengan demikian, perusahaan akan selalu menjadi pilihan utama pelanggan dibandingkan dengan kompetitornya.

Penelitian terkait pengaruh intellectual capital terhadap kinerja keuangan pernah dilakukan oleh beberapa peliti, yaitu (Cy et al., 2017; Sardo \& Serrasqueiro, 2018; Yuskar \& Novita, 2014). Ketiga penelitian tersebut menemukan bahwa intellectual capital berpengaruh positif secara signifikan terhadap kinerja keuangan. (Cy et al., 2017) meneliti pengaruh intellectucal capital terhadap kinerja keuangan pada bank komersial di Nigeria pada tahun penelitian antara 2010-2015. Penelitian menemukan bahwa ketiga komponen intellectual capital secara simultan berpengaruh positif signifikan terhadap kinerja keuangan.

H2: Intellectual capital berpengaruh positif terhadap kinerja keuangan

Kinerja manajemen perusahaan dalam mengelolan operasional perusahaan tercermin dalam kinerja keuangan. Semakin tinggi kinerja keuangan perusahaan, berarti semakin efektif dan efisien perusahaan dalam menggunakan sumber daya dan kemudian berkontribusi ada perekonomian makro suatu negara (Almajali et al., 2012). Investor akan mempertimbangkan kinerja keuangan sebagai salah satu acuan berinvestasi. Kinerja keuangan menjadi salah satu pertimbangan investor untuk melakukan evaluasi kondisi perusahaan secara keseluruhan. Informasi yang terkandung di laporan keuangan sebagai sarana bentuk pertanggungjawaban manajemen kepada stakeholders dan sebagai bahan pertimbangan pengambilan keputusan. Investor akan menilai bahwa perusahaan mempunyai prospek yang bagus apabila kinerja keuangan menunjukkan angka yang tinggi.

Penelitian yang dilakukan oleh (Hidayat \& Topowijono., 2018) menunjukkan bahwa kinerja keuangan berpengaruh positif terhadap harga saham. Menurut IAI (Ikatan Akuntansi Indonesia, 2012), kinerja keuangan adalah kefektifan manajemen perusahaan dalam mefungsingkan dan memberdayakan segala unsur yang ada di perusahaan, yang berarti juga semakin tinggi citra perusahaan di mata pihak luar.

H3: Kinerja Keuangan Berpengaruh Positif Terhadap Reaksi Investor

Intellectual capital semakin penting dalam pengetahuan ekonomi saat ini dan memainkan peran penting dalam inovasi, pertumbuhan produktivitas, kinerja dan daya saing organisasi. Manajemen intellectual capital adalah bidang yang melibatkan kreativitas dan kecerdasan masyarakat, metode manajemen baru, teknologi informasi baru, dan cara berpikir baru tentang organisasi pasca industri yang baru (Samira et al., 2017). Kamampuan (the employed capital) dan infrastruktur yang baik (structural capital) menjadi pendukung kompetensi dan 
komitemen (human capital) Komponen

mengoptimalkan intellectual capital tersebut menjadi kombinasi yang dapat perusahaan maka perusahaan akan meningkatkan kinerja keuangan serta produktivitas yang baik. Investor akan memilih perusahaan yang mempunyai kinerja keunagan yang baik, yang pada akhirnya akan mendorong kenaikan harga saham dan nilai perusahaan (Nuryaman, 2015).

Penelitian yang dilakukan oleh (Alipour, 2012) menunjukkan bawah intellectual capital mempunyai pengaruh signifikan positif terhadap kinerja keuangan perusahaan. Semakin baik perusahaan mendapatkan laba yang tinggi pula. Sedangkan penelitian yang dilakukan oleh (Shabani et al., 2013) menunjukkan bahwa terdapat hubungan yang positif antara kinerja keuangan dengan harga saham. Artinya, semakin tinggi kinerja keuangan suatu perusahaan akan mempengaruhi minat investor terhadap saham perusahaan tersebut.

H4: Kinerja keuangan memediasi pengaruh Intellectual capital terhadap kinerja keuangan

\section{MODEL PENELITIAN}

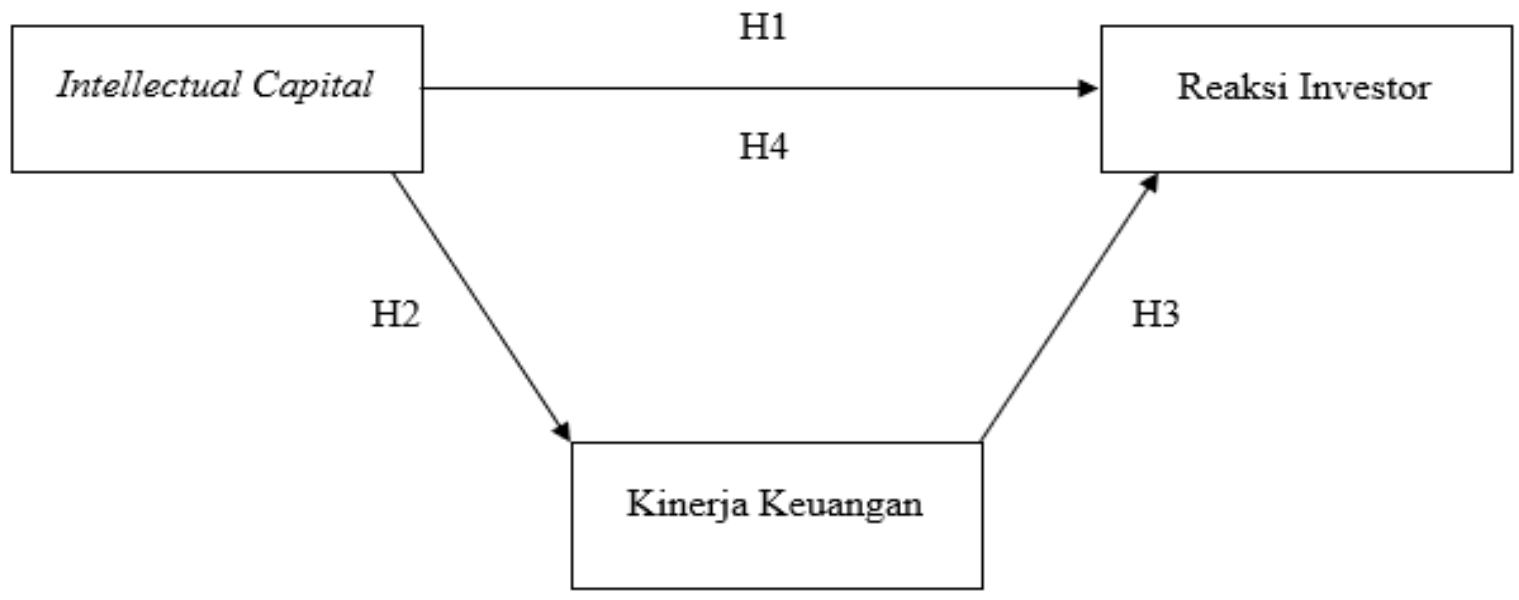

Gambar 1. Model Penelitian

\section{METODE PENELITIAN}

Menurut (Indriantoro \& Supomo, 1999), sampel adalah kelompok atau sebagian kelompok dari elemen-elemen populasi. Pemilihan sampel pada penilitian ini menggunakan prosedur penyampelan nonprobabilitas, yaitu purposive sampling. Menurut (Abdillah \& Jogiyanto, 2015), teknik penyampelan bertujuan (purposive sampling) adalah teknik pemilihan sampel berdasarkan kriteria tertentu dan penilaian peneliti untuk mengarahkan sampel terpilih sesuai dengan tujuan penelitian. Periode penelitian adalah tahun 2016-2018. Berikut kriteria penentuan perusahaan sampel: 
1. Perusahaan sektor perbankan yang terdaftar di BEI sejak Januari 2016

2. Perusahaan sektor perbankan yang terdaftar di BEI sampai akhir tahun 2018, sehingga menghasilkan laporan keuangan periode akhir tahun 2018

3. Perusahaan sektor perbankan yang menerbitkan laporan keuangan 2016 sampai dengan 2018 secara berturutturut

Penelitian ini merupakan penelitian kuantitatif yang menggunakan data sekunder. Data yang diperlukan dalam penelitian ini meruapkan data sekunder yang berasal dari laporan keuangan perusahaan yang diperoleh dari situs resmi Bursa Efek Indonesia, yaitu https://www.idx.co.id/ dan situs masing-masing perusahaan. Selain itu, peneliti juga mendapatkan data terkait harga saham perusahaan di situs yahoo finance, yaitu https://finance.yahoo.com.

\section{Definisi Operasional Variabel Intellectual capital}

Penelitian ini menggunakan metode Value Added Intellectual Coeffiecient (VAIC ${ }^{\mathrm{TM}}$ ) yang dikembangkan oleh (Pulic, 2000) untuk mengukur intellectual capital. VAIC ${ }^{\mathrm{TM}}$ diukur berdasarkan value added yang diciptakan oleh komponen intellectual capital yang terdiri dari value added of capital employee (VACE), value added of human capital (VAHC), dan structural capital value added (SCVA). Konsep utama VAICTM adalah manusia sebagai sumber daya yang mempunyai potensi pengetahuan bertanggung jawab terhadap keberhasilan dan kinerja setiap perusahaan (Ulum, 2008). Oleh karena itu, biaya gaji karyawan menjadi variabel vital dalam konteks perhitungan VAIC $^{\mathrm{TM}}$. Berikut adalah formula dan tahapan perhitungan VAIC ${ }^{\mathrm{TM}}$ :

a. Menghitung Value Added (VA).

$\mathrm{VA}=$ OUT-IN

- Output (OUT) - Total Penjualan dan pendapatan lain

- $\quad$ Input (IN) - Beban penjualan dan biayabiaya lain

- Value Added (VA) - Selisih antara Output dan Input

b. Menghitung Value Added Capital Employed (VACE)

$V A C E=\frac{\mathrm{VA}}{\mathrm{CE}}$

- Capital Employed (CE) - Dana yang tersedia (Laba bersih dan Ekuitas)

- Value Added Capital Employed (VACE) - Rasio dari VA terhada CE yang menunjukkan kontribusi yang dibuat oleh setiap unit dari CE terhadap value added perusahaan/organisasi

c. Menghitung Value Added Human Capital (VAHC)

$V A H C=\frac{\mathrm{VA}}{\mathrm{HC}}$

- Value Added Human Capital (VAHC) Rasio dari VA terhadap HC yang menunjukkan kontribusi yang dibuat oleh setiap rupiah yang diinvestasikan dalam HC terhadap value added perusahaan/organisasi

d. Menghitung Structural Capital Value Added (SCVA) 
$S C V A=\frac{\mathrm{SC}}{\mathrm{VA}}$

- Structural Capital Value Added (SCVA)

- Rasio untuk mengukur jumlah SC yang dibutuhkan untuk menghasilkan 1 rupiah dari VA dan merupakan indikasi keberhasilan SC dalam penciptaan nilai

e. Menghitung Value Added Intellectual capital (VAICTM)

$\mathrm{VAIC}^{\mathrm{TM}}=\mathrm{VACE}+\mathrm{VAHC}+\mathrm{SCVA}$

\section{Kinerja Keuangan}

Kinerja keuangan pada penelitian ini diukur menggunakan return on assets (ROA). ROA sebagai salah satu pengukuran kinerja tradisional digunakan untuk mewakili kinerja keuangan perbankan. ROA merupakan pengukuran kunci dari profitabilitas perbanakan (Dietrich \& Wanzenried, 2011; Pasiouras \& Kosmidou, 2007). ROA dihitung dengan cara membagi Laba Bersih dengan Total Asset

$R O A=\frac{\text { Laba Bersih }}{\text { Total Aset }}$

\section{Reaksi Investor}

Penelitian ini menggunakan cummulative abnormal return untuk mengukur reaksi investor. Menurut (Bodie et al., 2014) abnormal return adalah selisih imbal hasil aktual dengan tolak ukurnya. Sedangkan menurut (Halim, 2010), abnormal return adalah selisih antara return sesungguhnya atau return aktualisasi (realized return) dengan return ekspektasi (expected return). Oleh karena itu, cummulative abnormal return adalah akumulasi dari selisih return realisasi dan return ekspektasi. Berikut beberapa tahapan untuk menghitung cumulative abnormal return:

1. Menghitung actual return saham selama event period

$$
\boldsymbol{R}_{i t}=\frac{\left(\boldsymbol{P}_{i t}-\boldsymbol{P}_{i t-1}\right)}{\boldsymbol{P}_{i t-1}}
$$

Keterangan:

$\mathrm{R}_{\text {it }} \quad=$ Return saham $\mathrm{i}$ pada hari $\mathrm{t}$

$\mathrm{P}_{\mathrm{it}} \quad=$ Harga saham $\mathrm{i}$ pada hari $\mathrm{t}$

$\mathrm{P}_{\mathrm{it}-1} \quad=$ Harga saham $\mathrm{i}$ pada hari $\mathrm{t}-1$

2. Menghitung expected return saham harian selama event period

$$
E\left(R_{i t}\right)=R_{m t}
$$

Keterangan:

$$
\begin{aligned}
& \mathrm{E}\left(\mathrm{R}_{\mathrm{it}}\right)=\text { Expected return saham } \mathrm{i} \\
& \mathrm{R}_{\mathrm{mt}}=\text { Return pasar pada hari } \mathrm{t}
\end{aligned}
$$

Karena nilai expected return saham sama dengan return pasar, maka rumus expected return menggunakan rumus return pasar sebagai berikut:

$$
R_{m t}=\frac{\left(I H S D G_{t}-P_{t-1}\right)}{I H S G_{t-1}}
$$

Keterangan:

$$
\begin{array}{ll}
\mathrm{R}_{\mathrm{mt}}= & \text { Return pasar pada hari } \mathrm{t} \\
\mathrm{IHSG}_{\mathrm{t}}= & \text { Index harga saham } \\
& \text { gabungan pada hari } \mathrm{t}
\end{array}
$$



$\mathrm{IHSG}_{\mathrm{t}-1} \quad=\quad$ Index harga saham Gabungan pada hari t-1

3. Menghitung abnormal return saham selama event period

$$
A R_{i t}=R_{i t}-E\left(R_{i t}\right)
$$

Keterangan:

$\mathrm{AR}_{\text {it }}=$ Abnormal return saham i pada hari $\mathrm{t}$

$\mathrm{R}_{\text {it }}=$ Actual return saham $\mathrm{i}$ pada hari $\mathrm{t}$

$\mathrm{E}\left(\mathrm{R}_{\mathrm{it}}\right)=$ Expected return saham $\mathrm{i}$ pada hari $\mathrm{t}$

Karena penelitian ini mengasumsikan bahwa expected return semua sama sama dengan expected return, maka diperoleh rumus sebagai berikut:

$$
\boldsymbol{A R}_{i t}=\boldsymbol{R}_{i t}-\boldsymbol{R}_{\boldsymbol{m} t}
$$

$$
\begin{aligned}
\mathrm{AR}_{\mathrm{it}}= & \text { Abnormal return saham } \mathrm{i} \\
& \text { pada hari } \mathrm{t} \\
\mathrm{R}_{\mathrm{it}}= & \text { Actual return saham } \mathrm{i} \text { pada } \\
& \text { hari } \mathrm{t} \\
\mathrm{R}_{\mathrm{mt}}= & \text { Return pasar pada hari } \mathrm{t}
\end{aligned}
$$

4. Menghitung cumulative abnormal return dari abnormal return harian t-3 sampai dengan $t+3$ dengan rumus sebagai berikut:

$$
C A R_{i t} \sum_{t=-3}^{t=+3} A R_{i t}
$$

$\mathrm{CAR}_{\mathrm{Nn}}=$ Akumulasi abnormal return harian masing-masing saham

\section{Metode dan Teknik Analisis Data}

Penelitian ini menggunakan Structural Equation Modeling (SEM) untuk analisis data dan pengujian hipotesis. SEM memberikan kemampuan untuk melakukan analisis jalur (path analysis) yang memungkinkan peneliti untuk mengestimasi pengaruh langsung, pengaruh tidak langsung maupun pengaruh total (Ghozali, 2008). SEM adalah suatu teknik statistika untuk menguji dan mengestimasi hubungan kasula dengan mengintegrasi analisis faktor dan analisis jalur (Haavelmo, 1943). Software yang digunakan sebagai alat analisis adalah WarpPLS versi 7.0. Penggunaaan PLS-SEM digunakan untuk mengatasi masalah regresi berganda, misalnya jumlah sampel yang sedikit.

\section{E. HASIL DAN PEMBAHASAN}

\section{Statistik Deskriptif}

\begin{tabular}{|c|c|c|c|c|c|}
\hline & $\mathbf{N}$ & Minimum & Maximum & Mean & Std. Deviation \\
\hline InC & 102 & $-2,001$ & 12,382 & 3,368 & 2,57 \\
\hline FiP & 102 & $-0,112$ & 0,043 & 0,007 & 0,021 \\
\hline InR & 102 & $-0,148$ & 0,995 & 0,013 & 0,120 \\
\hline
\end{tabular}

Sumber: Data sekunder yang telah diolah 
Hasil perhitungan intellectual capital berdasarkan model VAICTM diklasifikasikan ke dalam 4 kategori yang didasarkan pada skor VAICTM masing-masing bank, yaitu (Ulum, 2008):

1. Top performers - skor VAIC ${ }^{\mathrm{TM}}$ di atas 3

2. Good performers - skor VAIC ${ }^{\mathrm{TM}}$ antara 2,0 sampai 2,99

3. Common performers - skor VAIC ${ }^{\mathrm{TM}}$ antara 1,5 sampai 1,99

4. Bad performers - skor VAIC ${ }^{\mathrm{TM}}$ di bawah 1,5

Dari tabel 2 di atas, dapat dilihat bahwa nilai minimum intellectual capital $(\ln C)$ adalah -2,001, nilai maksimum adalah 12,382, sedangkan nilai rata-rata adalah 3,368. Berdasarkan klasifikasi nilai VAIC $^{\mathrm{TM}}$ rata-rata perbankan di Indonesia sudah mencapai tahap top performers, meskipun masih ada beberapa bank yang berada pada bad performers. Kemudian, nilai minumum dari kinerja keuangan (FiP) adalah -0,112, nilai maksimum adalah 0,043, sedangkan nilai rata-ratanya adalah 0,007. Pada variabel ketiga, yaitu reaksi investor $(\ln R)$ memiliki nilai minimum $-0,148$, nilai maksium adalah 0,995, sedangkan nilai rata-rata adalah 0,013 .

\section{Analisis Partial Least Square}

\begin{tabular}{|c|c|c|c|}
\hline Hasil & P-Value & Kriteria & Keterangan \\
\hline $\mathrm{APC}=0.277$ & $\mathrm{P}<0.001$ & Good If $\mathrm{P}<0,05$ & Didukung \\
\hline $\mathrm{ARS}=0.142$ & $\mathrm{P}=0.035$ & Good If $\mathrm{P}<0,05$ & Didukung \\
\hline $\mathrm{AVIF}=1.012$ & & $\mathrm{P}<5$ & Didukung \\
\hline
\end{tabular}

Sumber: Output WarpPLS 7.0

Tabel 2 Nilai Goodness of Fit Model

PLS adalah salah satu metode statistika SEM berbasis varian yang didesain untuk menyelesaikan regresi berganda ketika terjadi permasalahan spesifik pada data, misalnya ukuran sampel penelitian yang kecil. Analisis WarpPLS 7.0 digunakan untuk melihat model fit indices dan hasil pengujian hipotesis. Berdasarkan perhitungan, nilai $Q$-square predictive

\section{Analisis Variabel Mediasi}

Variabel mediasi adalah variabel penyela yang terletak di antara variabel independen dan dependen, sehingga relevance adalah 0,264. Artinya, Intellectual capital mampu menjelaskan reaksi investor dan kinerja keuangan sebesar $26,4 \%$ dan sisanya 73,6 dijelaskan oleh variabel lain di luar penelitian ini. Ketiga indikator yang menjelaskan nilai goodness of fit model menunjukkan bahwa ketiganya didukung. Hal ini berarti bahwa model penelitian dapat digunakan untuk menguji hipotesis.

variabel independen tidak langsung mempengaruhi berubahnya atau timbulnya variabel dependen (MacKinnon et al., 2012). Pola hubungan antara variabel secara 
langsung tanpa variabel mediasi dapat dilihat pada :

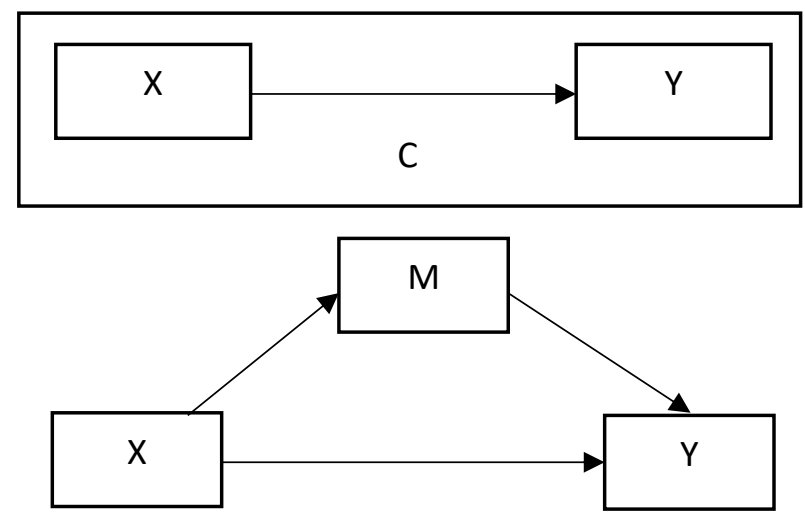

pengujian analisis variabel mediasi yang dilakukan dengan kausal step yang dikembangkan oleh Baron and Kenny (1986). Variabel M dinyatakan sebagai variabel mediasi jika memenuhi kriteria sebagai berikut:

1. Jika variabel independent (X) berpengaruh terhadap variabel dependen $(Y)$

2. Jika variabel independent (X) berpengaruh terhadap variabel yang diduga sebagai variabel mediasi (M)

3. Jika variabel yang diduga sebagai variabel mediasi (M) berpengaruh terhadap variabel dependen (Y)

Adapun kretiria pengujian adalah sebagai berikut (Suliyanto, 2011):

1. Variabel $M$ dinyatakan sebagai variabel mediasi sempurna (perfect mediation) jika setelah memasukkan varibel $M$, pengaruh variabel $X$ terhadap $Y$ yang tadinya signifikan (sebelum memasukkan variabel $\mathrm{M}$ ) menjadi tidak signifikan setelah memasukkan variabel $M$ ke dalam model penelitian

2. Variabel $M$ dinyatakan sebagai variabel mediasi parsial (partial mediation) jika setelah memasukkan variabel $M$, pengaruh variabel $X$ terhadap $Y$ yang tadinya signifikan (sebelum memasukkan variabel $\mathrm{M}$ ) menjadi tetap signifikan setelah memasukkan variabel $\mathrm{M}$ ke dalam model penelitian

\section{Pembahasan}

\section{Pengaruh Intellectual capital terhadap reaksi investor}

Perusahaan yang memiliki intellectual capital yang unggul akan dihargai lebih oleh stakeholder karena kepentingan stakeholder dapat terpenuhi dengan intellectual capital yang lebih unggul dibandingkan dengan yang lain (Yuskar \& Novita, 2014). Penciptaan nilai (value creation) yang dilakukan melalui optimalisasi 
human capital, aset fisik dan structural capital akan menciptakan keunggulan kompetitif bagi perusahaan. Dengan demikian, stakeholder akan mempunyai persepsi yang bagus terhadap perusahaan karena dinilai mempunyai keunggulan kompetitif untuk bersaing di lingkungan bisnis yang dinamis. Penilaian stakeholder, dalam hal ini investor akan meningkat ketika mengetahui bahwa sumber daya manusia dikelola dengan baik.

Berdasarkan pada hasil pengujian hipotesis pertama pada tabel 4 terlihat bahwa $p$-value $(0,01)$ lebih kecil dari tingkat signifikansi yang ditetapkan $(\leq 0,05)$ dan nilai koefisien jalur bertanda positif 0,22. Hal ini menunjukkan bahwa hipotesis pertama didukung, artinya intellectual capital berpengaruh positif terhadap reaksi investor. Perusahaan yang mampu mengotimalkan intellectual capital akan mendapat persepsi yang baik dari investor. Hipotesis pertama mendukung penelitian (Ronaldo et al., 2017) yang menemukan bahwa intellectual capital berpengaruh positif dan signifikan terhadap nilai perusahaan di Indonesia.

\section{Pengaruh Intellectual capital terhadap kinerja keuangan}

Sumber daya intellectual capital merupakan komponen vital dan strategis yang dimiliki manajemen dan mampu mengarahkan manajemen pada keunggulan kompetitif yang berkelanjutan dan kinerja keuangan yang unggul (Ahangar, 2011). Intellectual capital adalah aset penting perusahaan yang dapat digunakan untuk mendapatkan keuntungan, pelanggan baru, menciptakan produk baru, atau meningkatkan bisnis (Paradesia et al., 2016). Dengan kata lain, intellectual capital dapat menjadi komponen vital bagi perusahaan untuk meningkatkan dan mendorong kinerja keuangan secara optimal.

Berdasarkan pada hasil pengujian hipotesis kedua pada tabel 4 terlihat bahwa $p$-value $(<0,01)$ lebih kecil dari tingkat signifikansi yang ditetapkan $(\leq 0,05)$ dan nilai koefisien jalur bertanda positif 0,42 . Hal ini menunjukkan bahwa hipotesis pertama didukung, artinya intellectual capital berpengaruh positif terhadap kinerja keuangan. Perusahaan yang mempunyai intellectual capital yang optimal akan mendapatkan keuntungan secara finansial atau mendapatkan kinerja keuangan yang baik pula. Hasil dari hipotesis kedua mendukung penelitian Sardo and Serrasqueiro (2018) dan William, Gaetano and Giuseppe (2019) yang menyatakan bahwa intellectual capital mempunyai dampak positif dan signifikan terhadap kinerja keuangan.

\section{Pengaruh kinerja keuangan terhadap reaksi investor}

Kondisi keuangan yang baik akan membuat kemampuan perusahaan untuk mendistribusikan dividen akan lebih besar. Hal ini berarti bahwa dapat menggunakan modal dengan baik, sehingga investor percaya bahwa perusahaan akan memberikan laba yang lebih besar, dan itu akan berpengaruh pada kenaikan harga 
saham (Christina \& Robiyanto, 2018). Sinyal positif yang dapat dilihat dari profitabilitas perusahaan akan dapat meningkatkan harga saham perusahaan sehingga memberikan kontribusi positif terhadap nilai perusahaan (Wijayanto et al., 2019). Secara sederhana, dapat dikatakan bahwa perusahaan yang memiliki kinerja keuangan yang baik akan mendapatkan perspektif yang baik dari investor dan secara langsung akan meningkatkan harga saham perusahaan tersebut.

Berdasarkan tabel 4, hasil pengujian menunjukkan bahwa hipotesis ketiga mempunyai $p$-value $(0,05)$ yang sama dengan nilai signifikansi yang telah ditetapkan $(0,05)$ dan nilai koefisien jalur bertanda positif $(0,16)$. Hal ini berarti bahwa hasil pengujian mendukung hipotesis ketiga, yaitu kinerja keuangan berpengaruh positif terhadap reaksi investor. Hasil ini mendukung penelitian (Ligocka \& Stavárek, 2019; Shabani et al., 2013) yang menunjukkan bahwa kinerja keuangan mempunyai pengaruh terhadap nilai saham suatu perusahaan.

\section{Kinerja keuangan memediasi pengaruh intellectual capital terhadap reaksi investor}

Keunggulan bersaing dapat didapatkan perusahaan ketika perusahaan mampu menggunakan teknologi secara optimal dan mampu mengelola sumber daya yang dimiliki secara efektif dan efisien (Paradesia et al.,
2016). Menurut Chen, Cheng and Hwang (2005), intellectual capital merupakan sumber daya yang terukur untuk meningkatkan competitive advantages dan akan memberikan kontribusi kinerja keuangan dan meningkatkan nilai perusahaan. Di satu sisi, rasio keuangan menjadi salah satu alat vital bagi investor untuk mengevaluasi investasi, karena rasio keuangan menjadi cerminan tinggi atau rendahnya nilai perusahaan (Yuskar \& Novita, 2014).

Berdasarkan hasil pengujian pada tabel 5, dapat disimpulkan bahwa kinerja keuangan dapat memediasi secara penuh pengaruh intellectual capital terhadap reaksi investor. Hal itu dapat dibuktikan dengan adanya perubahan nilai koefisien dan $p$-value antara pengaruh langsung dan pengaruh tidak langsung intellectual capital pada reaksi investor. Pengaruh langsung intellectual capital terhadap reaksi investor adalah signifikan dengan nilai koefisien jalur 0,22 dan $p$-value 0,01 , sedangkan pengaruh tidak langsung intellectual capital terhadap reaksi investor dengan dimediasi kinerja keuangan adalah tidak signifikan dan menghasilkan nilai koefisien jalur 0,072 dan p-value 0,147. Mengacu pada persyaratan variabel mediasi dalam penelitian Baron \& Kenny 11986), dapat disimpulkan bahwa kinerja keuangan dapat memediasi secara penuh pengaruh intellectual capital terhadap reaksi investor dan hipotesis kelimat didukung. 


\begin{tabular}{|c|c|c|c|c|c|c|}
\hline Hipotesis & Prediksi & Variabel & Koef Jalur & $\boldsymbol{P}$-value & Signifikansi & Hasil \\
\hline H1 & + & InC-InR & 0.22 & $\mathrm{P}=0.01$ & Signifikan & Didukung \\
\hline H2 & + & InC-FiP & 0.45 & $\mathrm{P}<0.01$ & Signifikan & Didukung \\
\hline H3 & + & FiP-InR & 0.16 & $\mathrm{P}=0.05$ & Signifikan & Didukung \\
\hline
\end{tabular}

Sumber: Data sekunder yang telah diolah Tabel 3 Ringkasan Hasil Uji Pengaruh Langsung

\begin{tabular}{|c|c|c|c|c|}
\hline & \multicolumn{2}{|c|}{ Direct Effect } & \multicolumn{2}{c|}{ Indirect Effect } \\
\cline { 2 - 5 } & Koefisien Jalur & $P$-value & Koefisien Jalur & $P$-value \\
\hline InC-InR & 0.22 & $\mathrm{P}=0.01$ & 0,072 & 0.147 \\
\hline InC-FiP & 0.45 & $\mathrm{P}<0.01$ & & \\
\hline FiP-InR & 0.16 & $\mathrm{P}=0.05$ & & \\
\hline
\end{tabular}

Sumber: Data sekunder yang telah diolah

Tabel 4 Hasil Pengujian Hipotesis Empat

\section{F. Kesimpulan}

Berdasarkan hasil pengujian dan pembahasan diperoleh beberapa kesimpulan. Pertama, intellectual capital berpengaruh positif dan signifikan terhadap reaksi investor, kedua intellectual capital berpengaruh positif dan signifikan terhadap kinerja keuangan, ketiga kinerja keuangan berpengaruh positif dan signifikan terhadap reaksi investor, dan keempat kinerja keuangan memediasi secara penuh pengaruh intellectual capital terhadap reaksi investor.

\section{Dengan kemampuan kinerja} keuangan dalam memediasi pengaurh intellectual capital terhadap reaksi investor, dapat disimpulkan bahwa pasar akan memberikan penilaian tinggi terhadap perusahaan yang mempunyai kinerja keuangan yang tinggi. Intellectual capital yang dikelola secara optimal akan memberikan keuntungan secara finansial bagi perusahaan. Selanjutnya, kondisi keuangan yang bagus akan direspon secara positif oleh pasar, hingga pada akhirnya nilai perusahaan semakin tinggi dengan ditunjukkannya harga saham yang tinggi pula. Berdasarkan kesimpulan pada penelitian ini, terdapat implikasi yang dapat menjadi perhatian manajemen bank, yaitu manajemen bank perlu memperhatikan dan mengelola intellectual capital secara optimal dan mengevaluasi kinerja bank karena terbukti komponen tersebut mempu menjadi komponen yang akan direspon positif oleh investor dan pada akhirnya akan meningkatkan nilai perusahaan. Selain itu, penelitian ini dapat dimanfaatkan sebagai salah satu acuan dalam pengambilan keputusan bagi stakeholder. 


\section{REFERENSI}

Abdillah, W., \& Jogiyanto, H. (2015). Partial Least Square (PLS) Alternatif Structural Equation Modeling (SEM) dalam Penelitian Bisnis. In book.

Ahangar, R. G. (2011). The relationship between intellectual capital and financial performance: An empirical investigation in an Iranian company. African Journal of Business Management.

https://doi.org/10.5897/AJBM10.712

Alipour, M. (2012). The effect of intellectual capital on firm performance: An investigation of Iran insurance companies. Measuring Business Excellence.

https://doi.org/10.1108/136830412112 04671

Almajali, A. Y., Alamro, S. A., \& Al-Soub, Y. Z. (2012). Factors Affecting the Financial Performance of Jordanian Insurance Companies Listed at Amman Stock Exchange. Journal of Management Research. https://doi.org/10.5296/jmr.v4i2.1482

Anicic, J., Anicic, D., \& Majstorovic, A. (2017).

Accounting and financial reports in the function of corporate governance. Journal of Process Management. New Technologies.

https://doi.org/10.5937/jouproman513302

Ayuni, A. D. N. (2016). Pengaruh Kinerja Keuangan Dan Kebijakan Dividen Terhadap Reaksi Investor Pada
Perusahaan Otomotif. Jurnal IImu Dan Riset Akuntansi.

Baron, R. M., \& Kenny, D. A. (1986). The moderator-mediator variable distinction in social psychological research: Conceptual, strategic, and statistical considerations. Journal of Personality and Social Psychology. https://doi.org/10.1037//0022-

3514.51.6.1173

Bhunia, A., Mukhuti, S. S., \& Roy, S. G. (2011). Financial Performance Analysis-A Case Study. Current Research Journal of Social Sciences.

Bodie, Z., Kane, A., \& Marcus, A. J. (2014). "Manajemen Portofolio dan Investasi." In 1.

Bontis, N., Seleim, A., \& Ashour, A. (2007). Human capital and organizational performance: A study of Egyptian software companies. Management Decision.

https://doi.org/10.1108/002517407107 46033

Chen, M. C., Cheng, S. J., \& Hwang, Y. (2005). An empirical investigation of the relationship between intellectual capital and firms' market value and financial performance. Journal of Intellectual Capital.

https://doi.org/10.1108/146919305105 92771

Chi, C. W., Lieu, P. T., Hung, K., \& Cheng, H. W. (2016). Do industry or firm effects drive performance in Taiwanese knowledge-intensive industries? Asia 
Pacific Management Review.

https://doi.org/10.1016/j.apmrv.2016.05 .001

Christina, O., \& Robiyanto. (2018). The Effect of Financial Performance and Firm Size on Stock Prices of Manufacturing Company in 2013-2016. Prosiding SENDI_U.

Cy, O. O., Ph, D., Ndubuisi, A. N., \& Ph, D. (2017). Effect of Intellectual Capital on Financial Performance of Quoted Deposit Money Banks in Nigeria (20102015). Journal of Global Accounting.

Davenport, T. H., \& Prusak, L. (1998). Working knowledge : how organizations manage what they know / Thomas $\mathrm{H}$. Davenport, Laurence Prusak. In International Journal of Computer Science Issues (IJCSI).

Dietrich, A., \& Wanzenried, G. (2011). Determinants of bank profitability before and during the crisis: Evidence from Switzerland. Journal of International Financial Markets, Institutions and Money. https://doi.org/10.1016/j.intfin.2010.11. 002

Dženopoljac, V., Janoševic, S., \& Bontis, N. (2016). Intellectual capital and financial performance in the Serbian ICT industry. Journal of Intellectual Capital. https://doi.org/10.1108/JIC-07-20150068

Edvinsson, L. (1997). Developing intellectual capital at Skandia. Long Range Planning. https://doi.org/10.1016/s0024-

6301(97)90248-x

Faza, M. F., \& Hidayah, E. (2014). Pengaruh Intellectual Capital terhadap Profitabilitas, Produktivitas, dan Nilai Perusahaan pada Perusahaan Perbankan yang Terdaftar di Bursa Efek Indonesia (BEI). Ekbisi.

Fidhayatin, S. K., \& Uswati Dewi, N. H. (2012). ANALISIS NILAI PERUSAHAAN, KINERJA PERUSAHAAN DAN KESEMPATAN BERTUMBUH PERUSAHAAN TERHADAP RETURN SAHAM PADA PERUSAHAAN MANUFAKTUR YANG LISTING DI BEI. The Indonesian Accounting

Review. https://doi.org/10.14414/tiar.v2i02.96

FitzPatrick, M., Davey, J., Muller, L., \& Davey, H. (2013). Value-creating assets in tourism management: Applying marketing's service-dominant logic in the hotel industry. Tourism Management.

https://doi.org/10.1016/j.tourman.2012. 11.009

Ghosh, S., \& Mondal, A. (2009). Indian software and pharmaceutical sector IC and financial performance. Journal of Intellectual

Capital. https://doi.org/10.1108/146919309109 77798

Ghozali, I. (2008). SEM Metode Alternatif dengan PLS. In Semarang: Badan Penerbit Universitas Diponegoro.

Haavelmo, T. (1943). The Statistical 
Implications of a System of Simultaneous Equations.

Econometrica.

https://doi.org/10.2307/1905714

Halim, A. (2010). Analisis Investasi dan Aplikasinya. Mitra Wacana Media.

Harrison, S., \& Sullivan, P. H. (2000). Profiting from intellectual capital:Learning from leading companies. Journal of Intellectual Capital.

https://doi.org/10.1108/146919300103 24124

Hidayat, D., \& Topowijono. (2018). Pengaruh Kinerja Keuangan Terhadap Harga Saham (Studi Pada Perusahaan Pertambangan Subsektor Pertambangan Minyak Dan Gas Bumi Yang Terdaftar Dibursa Efek Indonesia Periode 2013-2016). Jurnal Administrasi Bisnis.

Hitt, M. A., Bierman, L., Shimizu, K., \& Kochhar, R. (2001). Direct and moderating effects of human capital on strategy and performance in professional service firms: A resourcebased perspective. In Academy of Management Journal. https://doi.org/10.2307/3069334

Hsu, L. C., \& Wang, C. H. (2012). Clarifying the Effect of Intellectual Capital on Performance: The Mediating Role of Dynamic Capability. British Journal of Management.

https://doi.org/10.1111/j.1467-

8551.2010.00718.x
Ikatan Akuntansi Indonesia. (2012). Standar Akuntansi Keuangan. Salemba Empat. Indriantoro, N., \& Supomo, B. (1999). Metodologi Penelitian Bisnis untuk Akuntansi dan Manajemen. BPFE Yogyakarta.

Johnson, W. H. A. (1999). Integrative taxonomy of intellectual capital: Measuring the stock and flow of intellectual capital components in the firm. International Journal of Technology Management. https://doi.org/10.1504/ijtm.1999.00278 8

Joshi, M., Cahill, D., Sidhu, J., \& Kansal, M. (2013). Intellectual capital and financial performance: An evaluation of the Australian financial sector. Journal of Intellectual Capital. https://doi.org/10.1108/146919313113 23887

Kannan, G., \& Aulbur, W. G. (2004). Intellectual capital: Measurement effectiveness. In Journal of Intellectual Capital. https://doi.org/10.1108/146919304105 50363

Ligocka, M., \& Stavárek, D. (2019). The Relationship Between Financial Ratios and The Stock Prices of Selected European Food Companies Listed on Stock Exchanges. Acta Universitatis Agriculturae Et Silviculturae Mendelianae Brunensis, 67 (1), 299307.

https://doi.org/doi.org/10.11118/actaun 
201967010299

Liu, C. H. (2017). Creating competitive advantage: Linking perspectives of organization learning, innovation behavior and intellectual capital. International Journal of Hospitality Management.

https://doi.org/10.1016/j.ijhm.2017.06.0 13

MacKinnon, D. P., Coxe, S., \& Baraldi, A. N. (2012). Guidelines for the Investigation of Mediating Variables in Business Research. Journal of Business and Psychology. https://doi.org/10.1007/s10869-0119248-z

Montequín, V. R., Fernández, F. O., Cabal, V. A., \& Gutierrez, N. R. (2006). An integrated framework for intellectual capital measurement and knowledge management implementation in small and medium-sized enterprises. Journal of Information Science. https://doi.org/10.1177/016555150606 7127

Nuryaman. (2015). The Influence of Intellectual Capital on The Firm's Value with The Financial Performance as Intervening Variable. Procedia - Social and Behavioral Sciences. https://doi.org/10.1016/j.sbspro.2015.1 1.037

O'Sullivan, K. J., \& Schulte, W. D. (2007). Models for human capital management: Human resource management of intellectual capital. International Journal of Learning and Intellectual Capital. https://doi.org/10.1504/IJLIC.2007.016 338

Ozkan, N., Cakan, S., \& Kayacan, M. (2017). Intellectual capital and financial performance: A study of the Turkish Banking Sector. Borsa Istanbul Review. https://doi.org/10.1016/j.bir.2016.03.00 1

Paradesia, N. E., Ilmi, Z., \& Nadir, M. (2016). Pengaruh Intellectual Capital Terhadap Abnormal Return Saham Dan Kinerja Keuangan (Studi Pada Perusahaan Perbankan Di Bursa Efek Indonesia Tahun 2011-2015). Jurnal Ekonomi Dan Manajemen.

Pasiouras, F., \& Kosmidou, K. (2007). Factors influencing the profitability of domestic and foreign commercial banks in the European Union. Research in International Business and Finance. https://doi.org/10.1016/j.ribaf.2006.03.0 07

Pulic, A. (1998). Measuring the performance of intellectual potential in the knowledge economy. The 2nd" World Congress on the Management of Intellectual Capital". Pulic, A. (2000). VAIC - an accounting tool for IC management. International Journal of Technology Management. https://doi.org/10.1504/ijtm.2000.00289 1

Pulic, A. (2004). Intellectual capital - does it create or destroy value? Measuring Business Excellence. https://doi.org/10.1108/136830404105 
24757

Reed, K. K., Lubatkin, M., \& Srinivasan, N. (2006). Proposing and testing an intellectual capital-based view of the firm. Journal of Management Studies. https://doi.org/10.1111/j.14676486.2006.00614.x

Ronaldo, Indriati, \& Fibria. (2017). The Effect of Intellectual Capital on Firm's Value using Ownership Structure as Moderating Variable on Company Listed in Indonesia Stock Exchange period 2008-2015. International Journal of Trend in Research and Development.

Ross, S. A. (1977). Determination Of Financial Structure: The IncentiveSignalling Approach. Bell $J$ Econ. https://doi.org/10.2307/3003485

Samira, B., Samia, A., \& Djamel, M. M. (2017). Intellectual capital and its measurement. Proceedings of the International Conference on Industrial Engineering and Operations Management.

Sardo, F., \& Serrasqueiro, Z. (2018). Intellectual capital, growth opportunities, and financial performance in European firms: Dynamic panel data analysis. Journal of Intellectual Capital.

https://doi.org/10.1108/JIC-07-20170099

Seyed Ali Akbar Ahmadi,. (2012). Intellectual capital management enablers in an Iranian context. AFRICAN JOURNAL OF BUSINESS MANAGEMENT. https://doi.org/10.5897/ajbm10.1619

Shabani, V., Aghaei, S. M. M., \& Shabani, V. (2013). Investigating the Relationship between Earnings and Stock Prices in Companies Accepted in the Stock Exchange : A Case Study in Iran ( 20002010 ). Natural and Social Sciences.

Subaida, I., Nurkholis, N., \& Mardiati, E. (2018). Effect Of Intellectual Capital And Intellectual Capital Disclosure On Firm Value. Jurnal Aplikasi Manajemen. https://doi.org/10.21776/ub.jam.2018.0 16.01 .15

Subramaniam, M., \& Youndt, M. A. (2005). The influence of intellectual capital on the types of innovative capabilities. In Academy of Management Journal. https://doi.org/10.5465/AMJ.2005.1740 7911

Suliyanto. (2011). Analisis Regresi Berganda. In Ekonometrika Terapan: Teori \& Aplikasi dengan SPSS.

Suryawijaya, M. A., \& Setiawan, F. A. (1998). Reaksi Pasar Modal Indonesia terhadap Peristiwa Politik Dalam Negeri (Event Study pada Peristiwa 27 Juli 1996). In KELOLA Gadjah Mada University Business Review.

Sveiby, K. E. (1997). The new organizational wealth: managing \& measuring knowledge-based assets. Choice Reviews

Online. https://doi.org/10.5860/choice.35-1000 Tarigan, J., Listijabudhi, S., Hatane, S. E., \& Widjaja, D. C. (2019). The Impacts of Intellectual Capital on Financial 
Performance: An Evidence From Indonesian Manufacturing Industry. Indonesian Journal of Business and Entrepreneurship.

https://doi.org/10.17358/ijbe.5.1.65

Tsakalerou, M. (2015). A meta-study of intellectual capital and firm performance: When the whole is more than the sum of its parts. International Journal of Learning and Intellectual Capital.

https://doi.org/10.1504/IJLIC.2015.070 168

Ulum, I. (2008). Intellectual Capital Performance Sektor Perbankan di Indonesia. Jurnal Akuntansi Dan Keuangan. https://doi.org/10.9744/jak.10.2.PP.7784

Wijayanto, A., Suhadak, Dzulkirom, M., \& Nuzula, N. F. (2019). The Effect Of Competitive Advantage On Financial Performance And Firm Value: Evidence From Indonesian Manufacturing Companies. Russian Journal of Agricultural and Socio-Economic Sciences. https://doi.org/10.18551/rjoas.2019-

01.04

William, F., Gaetano, M., \& Giuseppe, N. (2019). The impact of intellectual capital on firms financial performance and market value: Empirical evidence from Italian listed firms. African Journal of Business Management. https://doi.org/10.5897/ajbm2018.8725 Yuskar, Y., \& Novita, D. (2014). Analisis Pengaruh Intellectual Capital Terhadap Nilai Perusahaan Dengan Kinerja Keuangan Sebagai Variabel Intervening Pada Perusahaan Perbankan di Indonesia. Jurnal Manajemen Dan Bisnis Sriwijaya. https://doi.org/10.29259/jmbs.v12i4.31 84

Zhang, N. (2017). Relationship between Intangible Assets and Financial Performance of Listed Telecommunication Firms in China, based on Empirical Analysis. African Journal of Business Management. https://doi.org/10.5897/AJBM2017.842 9 